\title{
Effect of Both Phytoestrogen and Xenoestrogen on Some Sexual Hormones in Male Albino Rats and Illustration of The Effect of Arctium Lappa L
}

\section{(A. Lappa) on Their Actions}

Eman G.E. Helal ${ }^{1}$, Nora Abdulaziz Aljalaud ${ }^{2}$, Mohamed A. Abdelaziz ${ }^{3}$, Abeer Zakaria ${ }^{1}$

1-Zoology Department, Faculty of Science, Al- Azhar University (Girls),

2-Biology Department Collage of Science Imam Abdulrahman Bin Fasial University,

3- Physiology Department, Faculty of Medicine, Al-Azhar University,

*Corresponding Author: Eman G.E. Helal, E-mail: emanhelal@ hotmail.com, Mobile: 00201001025364 , Orchid.org/0000-0003-0527-7028.

\begin{abstract}
Background: Xenoestrogens are chemically distinct industrial products potentially able to disrupt the endocrine system by mimicking the action of endogenous steroid hormones. Phytoestrogens are naturally occurring non-steroidal plant chemicals that can act like the female hormone estrogen. Arctium lappa (burdock) root has traditionally been recommended as an aphrodisiac agent.

Objective: The aim of the study was to clarify the effect of both bisphenol-A (BPA) and anise oil together on some sexual hormones and illustration the effect of A. lappa on their actions.

Materials and methods: The study was conducted on thirty male albino rats. The animals were divided into three groups: Group I, control untreated group, Group II, rats treated with bisphenol-A and anise oil and Group III, rats treated with BPA and anise oil in addition to A. lappa. Blood samples were collected to estimate biochemical parameters. Results: The biochemical results showed highly significant increase $(\mathrm{p}<0.01)$ in the activities of ALT, AST, urea, creatinine, FSH, prolactin, total cholesterol, triglycerides, LDLC, VLDL, LDL/HDL and TC/HDL levels. While, there was highly significant decrease $(\mathrm{p}<0.01)$ in HDLC, total protein, albumin, globulin, testosterone and, LH. All these results turned back to the normal values after receiving the A. lappa as compared to normal group.

Conclusion: it could be concluded that phytoestrogen and xenoestrogen have undesirable effects and it's recommended to minimize the utilization of these compound to protect people from its hazardous effects.
\end{abstract}

Keywords: BPA, Anise oil, A. lappa, Hormonal assay, Biochemical parameters.

\section{INTRODUCTION}

The endocrine disrupter is defined as an exogenous substance or mixture that alter functions of endocrine system and consequently causes adverse effects in an intact organism ${ }^{(\mathbf{1})}$. These compounds that have endocrine disruption properties and activate estrogen receptors are called xenoestrogens (environmental estrogens). These compounds like estrogen in their effect but differ in structure ${ }^{(2)}$. They can be either synthetic or natural chemical compounds. Synthetic xenoestrogens include some widely used industrial compounds, such as bisphenolA (BPA), which is an estrogenic chemical able to interact with human estrogen receptors (ER). Many lines of evidence reveal that BPA has an impact as an endocrine disruptor even at low doses. BPA is a chemical used for lining metal cans and in polycarbonate plastics, such as baby bottles ${ }^{(3)}$. In rodents, BPA is associated with early sexual maturation, altered behavior and effects on prostate and mammary glands. In humans, BPA is associated with cardiovascular disease, diabetes and male sexual dysfunction in exposed workers. Food is a major exposure source. BPA can contaminate the environment in significant amounts by leaching from products (plastic food and water containers, dental sealants and some cash register receipts) and as byproducts of manufacturing ${ }^{(4)}$.
The herbs chosen for this study, contain phytoestrogens as shown from their chemical constituents. Anise (Pimpinella anisum L.), is a flowering plant in the family Apiaceae. It's also called aniseed ${ }^{(5)}$. Anise is a natural herbal plant that grows widely in Egypt and many Arab countries. Anise is commonly used in human nutrition to regulate the balance of somatic and sexual hormones. It contains essential oils and fatty acids, the main component of the essential oils is anethole and the biological properties are inhibiting bacterial ${ }^{(6)}$ and stimulating secretion of digestive enzyme and appetizing ${ }^{(7)}$. The taste and smell of the fruit are mainly due to the essential oil, which is $80-90 \%$ trans-anethole, with other components consisting of cis-anethole, safrole, estragole, $\mathrm{p}$-anisaldehyde, anisketone, linalool and bfarnesene 11. The seeds of anise contain 1.5-6\% essential oil, $10-20 \%$ fixed oil and $18 \%$ protein. The main constituents of the essential oil are $90 \%$ anethole, 2-4\% gamma-himachalene, < $1 \% \mathrm{p}-$ anisaldehyde, $0.9-1.5 \%$ methylchavicol, $3 \%$ cispseudoisoeugenyl 2- methylbutyrate and $1.3 \%$ transpseudoisoeugenyl 2-methylbutyrate ${ }^{(8)}$. The main constituent of the anise oil anethole, has been considered as the active estrogenic agent. Anethole causes premature thelarche, which is a common disorder characterized by breast development, usually younger than 2 years, with no other signs of puberty. Premature thelarche is usually associated with adrenal 
or ovarian disorders, hypothyroidism and use of exogenous hormones or drugs, and it may also be associated with long-term use of herbal medicine ${ }^{(9)}$.

Arctium lappa L is a traditional Chinese medicinal and an edible perennial plant of the family Compositae. It has also been used therapeutically in Europe, North America and Asia for hundreds of years. The plant has been cultivated as a vegetable in Japan for many years. Arctium lappa L. root is traditionally used in herbal remedies to treat tonsillitis, throat pain, arthritis, rashes and various skin problems, as a diuretic, diaphoretic and blood purifier ${ }^{\left({ }^{10}\right)}$. In traditional Chinese medicine, A. lappa root is recommended as an aphrodisiac agent, and used for the treatment of impotence and sterility, while Native Americans included the root in herbal

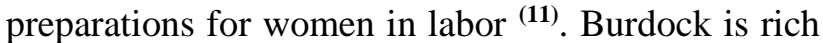
in antioxidant agents, such as tannin, gallic acid, arctigenin, quercetin and caffeoylquinic acid. Besides, it is good in treating pharyngitis as it can moisten lung for removing phlegm, wound healing and cures measles. In addition, arctigenin was first found with the ability of effectively improving memory impairment in mice ${ }^{(\mathbf{1 2})}$.

\section{MATERIALS AND METHODS}

30 male albino rats of local strain weighting 110$130 \mathrm{~g}$ were used throughout the experiments. The animals were housed in isolated animal metal cages in a conditioned room in the animal lab of the Physiology Department, Faculty of Science, AlAzhar University.

\section{Ethical approval:}

The study was approved by the Ethics Board of Al-Azhar University. This study was conducted in accordance with ethical procedures and policies approved by Animal Care and Use Committee of Faculty of science, Al-Azhar University, Cairo, Egypt.

Animals were treated according to guidelines for the use and care of laboratory animals regarding temperature, ventilation, humidity and normal dark / light cycle. The animals were allowed free access to water and fed on rodent chow diet all over the period of the work (30 days).

\section{Experimental design:}

In current study, 30 male albino rats were divided into three equal groups (10 rats in each group) as the following: Group I (control group), comprised of normal rats and maintained on standard rodent chow diet and tap water ad libitum for 30 days.

Group II, rats received orally anise oil $(1 \mathrm{ml} / \mathrm{kg}$ body weight) and BPA (20 mg $/ \mathrm{kg}$ body weight) for 30 days.

Group III, rats treated by BPA (20 $\mathrm{mg} / \mathrm{kg}$ body weight) with anise oil ( $1 \mathrm{ml} / \mathrm{kg}$ body weight) in addition to A. lappa ( $3 \mathrm{~g} / \mathrm{kg}$ body weight) for 30 days.
Body weight measurement: Body weight was recorded before and after the experiment.

Blood sample collection:

At the end of the experimental period, the blood samples were collected from the retro-orbital sinus after the animals were anesthetized by ether. Serum was separated by centrifugation at $3000 \mathrm{rpm}$ for 15 minutes at room temperature to estimate biochemical parameters.

\section{Biochemical analysis:}

Assessment of biochemical parameters:

In the present study total protein (TP) and albumin concentration were estimated, then serum globulin concentrations were calculated according to the formula: Globulin $(\mathrm{g} / \mathrm{dl})=$ total protein $(\mathrm{g} / \mathrm{dl})-$ albumin $(\mathrm{g} / \mathrm{dl})$. The ratio of serum albumin/globulin was determined. Aspartate aminotransferase (ASAT) and alanine aminotransferase (ALAT) activities, creatinine, urea concentrations as well as lipid profile [cholesterol, triglycerides and high-density lipoprotein cholesterol (HDL-C)] were also determined. All parameters were estimated using Bio Merieux SA kits, France. However, ratios of TC/HDL (risk factor 1) and LDL/HDL (risk factor 2) were also calculated after calculation of serum LDL-C (lowdensity lipoprotein cholesterol) and VLDL (very low density lipoprotein cholesterol) using the Friedwald's (13) and Norbert (14) formulas, respectively as following. Friedewald's equation: $\mathrm{LDL}(\mathrm{mg} / \mathrm{dl})=\mathrm{TC}$ $\{\mathrm{HDL}+[\mathrm{TG} / 5]\}$. Norbert equation: VLDL $=\mathrm{TG} / 5$.

\section{Hormonal assay:}

Estimation of serum luteinizing hormone (LH), follicles-stimulating hormone (FSH), Prolactin (P) and testosterone $(\mathrm{T})$ levels were determine by using manufacture instructions of kit. All kits used for hormone assay were from Monobind Inc. lake forest CA 92630, USA.

\section{Statistical analysis}

Recorded data were analyzed using the statistical package for social sciences, version 20.0 (SPSS Inc., Chicago, Illinois, USA). Quantitative data were expressed as mean \pm standard deviation (SD). Qualitative data were expressed as frequency and percentage.

\section{The following tests were done:}

- Independent-samples t-test of significance was used when comparing between two means.

- Chi-square $\left(\mathrm{x}^{2}\right)$ test of significance was used in order to compare proportions between two qualitative parameters.

- The confidence interval was set to $95 \%$ and the margin of error accepted was set to $5 \%$. The p-value was considered significant as the following:

- Probability (P-value)

- P-value $<0.05$ was considered significant.

- P-value $<0.001$ was considered as highly significant.

- P-value >0.05 was considered insignificant. 
RESULTS

Results of the present study showed significant increase in body weight in the mixture group and non-significant change in treated group with A. lappa when compared to control rats (Table1).

Table (1): Change of body weight in the control and treated groups.

\begin{tabular}{|l|l|l|l|}
\hline \multicolumn{1}{|c|}{ Groups } & $\begin{array}{l}\text { Control } \\
(\text { Mean } \pm \text { SEM) }\end{array}$ & $\begin{array}{l}\text { Mixture } \\
(\text { Mean } \pm \text { SEM })\end{array}$ & $\begin{array}{l}\text { Mixture and A. lappa } \\
(\text { Mean } \pm \text { SEM })\end{array}$ \\
\hline $\begin{array}{l}\text { \% of body weight change } \\
\text { from basal levels }\end{array}$ & $113.2 \pm \mathbf{0 . 0 4}$ & $117.4 * \pm 3.2$ & $117.0 \pm 1.8$ \\
\hline$\%$ change from control & & $3.71 \%$ & $3.5 \%$ \\
\hline
\end{tabular}

$\mathrm{P}^{*}<0.05$ as compared to control group.

\section{Protein profile:}

The present study showed a significant decrease $(\mathrm{p}<0.01)$ in total protein, albumin and globulin in mixture group, while showed insignificant change in total protein, albumin and globulin in A. lappa group when compared to control group (Table 2).

Table (2): Change in protein profile in the control and treated groups.

\begin{tabular}{|l|c|c|c|}
\hline Groups & $\begin{array}{c}\text { Control } \\
\text { (Mean } \pm \text { SEM) }\end{array}$ & $\begin{array}{c}\text { Mixture } \\
(\text { Mean } \pm \text { SEM) }\end{array}$ & $\begin{array}{c}\text { Mixture and A. lappa } \\
(\text { Mean } \pm \text { SEM) }\end{array}$ \\
\hline Total protein $(\mathrm{g} / \mathbf{d l})$ & $6.18 \pm 0.09$ & $4.0 \pm 0.07 * *$ & $5.5 \pm 0.11$ \\
\hline \% change from control & & $-35.3 \%$ & $-11.0 \%$ \\
\hline Albumin (g/dl) & $3.44 \pm 0,02$ & $2.0 \pm 0.06 * *$ & $3.1 \pm 0.07$ \\
\hline \% change from control & & $-41.9 \%$ & $-9.9 \%$ \\
\hline Globulin(g /dl) & $2.78 \pm 0.24$ & $2.0 \pm 0.1 * *$ & $2.4 \pm 0.09$ \\
\hline \% change from control & & $-28.1 \%$ & $-13.7 \%$ \\
\hline Albumin/Globulin & $1.30 \pm 0.21$ & $1.0 \pm 0.1$ & $1.29 \pm 0.06$ \\
\hline \% change from control & & $-23.1 \%$ & $-2.7 \%$ \\
\hline
\end{tabular}

\section{Liver functions:}

There was a significant increase $(\mathrm{p}<0.02)$ of ALT and AST activities in mixture group, and non-significant change in

A. lappa group when compared to control rats (Table 3).

Table (3): Change in liver function test in the control and treated groups.

\begin{tabular}{|l|l|l|l|}
\hline \multicolumn{1}{|c|}{ Grotps } & $\begin{array}{l}\text { Control } \\
\text { parameters }\end{array}$ & $\begin{array}{l}\text { Mixture } \\
(\text { Mean } \pm \text { SEM })\end{array}$ & $\begin{array}{l}\text { Mixture and A. lappa } \\
(\text { Sean } \pm \text { SEM })\end{array}$ \\
\hline ALT $($ U/dl) & $19.8 \pm 2.3$ & $27.0 \pm 0.052^{* *}$ & $26.3 \pm 0.06$ \\
\hline \% change from control & & $36.30 \%$ & $25.00 \%$ \\
\hline AST $($ U/dl) & $23.4 \pm 3.1$ & $34.0 \pm 0.005^{* *}$ & $30.0 \pm 0.07$ \\
\hline \% change from control & & $45.20 \%$ & $28.70 \%$ \\
\hline
\end{tabular}

$\mathrm{P}^{* *<0.001}$ as compared to control group

\section{Lipid profile:}

The present study showed a significant increase $(\mathrm{p}<0.01)$ in all the parameters of lipid profile, except HDL which recorded significant decrease $(\mathrm{p}<0.01)$ in mixture group and showed in significant change in A. lappa group when compared to control group (Table 4). 
Table (4): Changes in Lipid profile in the control and treated groups.

\begin{tabular}{|l|l|l|l|}
\hline $\begin{array}{c}\text { Groups } \\
\text { parameters }\end{array}$ & $\begin{array}{l}\text { Control } \\
(\text { Mean } \pm \text { SE) }\end{array}$ & $\begin{array}{l}\text { Mixture } \\
(\text { Mean } \pm \text { SE) }\end{array}$ & $\begin{array}{l}\text { Mixture and A. } \\
\text { lappa (Mean } \pm \text { SE) }\end{array}$ \\
\hline T-CH (mg/dl) & $142 \pm \mathbf{2 . 2}$ & $175.0 \pm \mathbf{0 . 1 7} * *$ & $151.6 \pm \mathbf{0 . 9}$ \\
\hline \% change from control & & $\mathbf{2 3 . 2 \%}$ & $\mathbf{6 . 7 \%}$ \\
\hline T-G (mg/dl) & $82 \pm 2.6$ & $103.2 \pm 0.17 * *$ & $91.1 \pm 0.71$ \\
\hline \% change from control & & $25.6 \%$ & $11.1 \%$ \\
\hline HDL-Cl (mg/dl) & $56 \pm 1.7$ & $42.0 \pm 0.9 * *$ & $52.3 \pm 0.005$ \\
\hline \% change from control & & $-25.0 \%$ & $-6.6 \%$ \\
\hline LDL-C & $70.6 \pm 1.8$ & $112.4 \pm 0.14 * *$ & $81.1 \pm 0.14$ \\
\hline \% change from control & & $59.2 \%$ & $14.9 \%$ \\
\hline VDL-C & $16.4 \pm 0.5$ & $20.6 \pm 0.14 * *$ & $18.4 \pm 0.14$ \\
\hline \% change from control & & $32.7 \%$ & $10.9 \%$ \\
\hline LDL/HDL & $1.27 \pm 0.04$ & $2.7 \pm 0.06^{* *}$ & $1.55 \pm 0.3$ \\
\hline \% change from control & & $112.6 \%$ & $22.9 \%$ \\
\hline TC/HDL & $2.56 \pm 2.4$ & $4.2 \pm 0.07 * *$ & $2.9 \pm 0.03$ \\
\hline \% change from control & & $102.34 \%$ & $13.3 \%$ \\
\hline
\end{tabular}

\section{Kidney functions:}

The data in table (5) showed a significant changes (0.01) in urea and serum creatinine in mixture group, while showed insignificant changes in A. lappa groups as compared to control group.

Table (5): Change in kidney function tests in the control and treated groups.

\begin{tabular}{|l|l|l|l|}
\hline $\begin{array}{c}\text { Groups } \\
\text { parameters }\end{array}$ & $\begin{array}{l}\text { Control } \\
(\text { Mean } \pm \text { SEM) }\end{array}$ & $\begin{array}{l}\text { Mixture } \\
(\text { Mean } \pm \text { SEM) }\end{array}$ & $\begin{array}{l}\text { Mixture and A. lappa } \\
\text { (Mean } \pm \text { SEM) }\end{array}$ \\
\hline Urea(mg/dl) & $40.2 \pm 0.9$ & $58 . \pm 1.3 * *$ & $47.6 \pm 0.11$ \\
\hline \% change from control & & $50.9 \%$ & $18.4 \%$ \\
\hline Creatinine(mg/dl) & $0.5 \pm 0.2$ & $0.7 \pm 0.07 * *$ & $0.62 \pm 0.07$ \\
\hline \% change from control & & $40 \%$ & $36 \%$ \\
\hline
\end{tabular}

$\mathrm{P}^{* *}<0.001$ as compared to control group

\section{Hormones:}

Results of the present study showed a significant increase $(\mathrm{p}<0.001)$ in the level of prolactin, FSH and LH levels and significant decrease in testosterone and LH levels in the mixture group when compared to the normal animal while showed insignificant changes in A. lappa groups .(Table 6 ).

Table (6): Changes in hormonal profile in the control and treated groups.

\begin{tabular}{|c|c|c|c|}
\hline $\begin{array}{l}\text { Groups } \\
\text { parameters }\end{array}$ & $\begin{array}{l}\text { Control } \\
(\text { Mean } \pm \text { SEM })\end{array}$ & $\begin{array}{l}\text { Mixture } \\
(\text { Mean } \pm \text { SEM })\end{array}$ & $\begin{array}{l}\text { mixture and A. lappa } \\
(\text { Mean } \pm \text { SEM) }\end{array}$ \\
\hline Prolactin (ng/ml) & $4.3 \pm 0.07$ & $\mathbf{6 . 0 \pm 0 . 0 7} * *$ & $5.1 \pm 0.06$ \\
\hline$\%$ change from control & & $39.5 \%$ & $19.1 \%$ \\
\hline Testosterone (ng/ml) & $16.2 \pm 0.6$ & $11.0 \pm 0.18 * *$ & $13.8 \pm 0.07$ \\
\hline \% change from control & & $-32 \%$ & $-8.7 \%$ \\
\hline FSH (mlu/ml) & $2.7 \pm 0.07$ & $3.9 \pm 0.07 * *$ & $2.3 \pm 0.1$ \\
\hline$\%$ change from control & & $44.4 \%$ & \\
\hline $\mathbf{L H}(\mathrm{mlu} / \mathbf{m l})$ & $10.7 \pm 0.5$ & $7.0 \pm 0.07 * *$ & $8.4 \pm 0.07$ \\
\hline \% change from control & & $-34.5 \%$ & $-9.1 \%$ \\
\hline
\end{tabular}

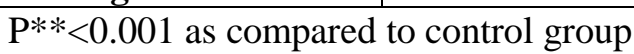


In the present study the mixture of bisphenol A and anise oil increased significantly the body weight. This effect may be attributed to the bio-actives compounds of aniseed such as anethole, eugenol, anisaldehyde, estragole and methylchavicol, which have a particular stimulant effect on digestive system. It was reported that anise oil affected positively the digestibility of nutrients. Indeed aniseed is rich in nutritive compounds, which can have a positive effect on body weight gain like proteins $18 \%$, fatty oil $8-23 \%$, essential oil $2-7 \%$, sugars $3-5 \%$ and crude fiber $12-15 \%{ }^{(15)}$.

\section{Liver function:}

In the present study, the increased activities of ALT and AST in mixture group might be due to BPA that have estrogen mimetic activity and can be cytotoxic. The metabolites of its toxicity were detected and characterized for the time in mammals namely isopropyl-hydroxyphenol that produced by the cleavage of BPA. Most of these metabolites apparently share a common metabolic pathway for which considerable evidence of the production of a reactive intermediate helps to explain BPA cytotoxicity (16). BPA can induce oxidative stress in the liver. It has been suggested that stress conditions in general induce elevation in the transamination pathway. AST and ALT are known to play a key role in mobilizing Laminoacids for gluconeogenesis and functions as link between carbohydrate and protein metabolisms under altered physiological, pathological and environmental conditions. Hence they are considered as sensitive indicators of stress. The aspartate and alanine aminotransferases are referred as "markers of cell injury", since they are first to leak out from the cell in the case of injury. BPA can induce hepatic damage and mitochondrial dysfunction by increasing oxidative stress in the liver ${ }^{(17)}$.

Also anise has toxic effect on the liver where it contain terpenes. Most of these terpenes easily enter the human body by oral absorption, penetration through the skin, or inhalation leading to measurable blood concentrations and liver toxicity, which is mainly based on reactive metabolites formation, increased concentration of reactive oxygen species and impaired antioxidant defense ${ }^{(18)}$. In addition, d-limonene shows hepatocyte morphological lesions including hydropic degeneration, microvesicular steatosis and necrosis, Kupfer cell hyperplasia and incipient fibrosis ${ }^{(19)}$. AST and ALT elevation was reduced in the animals treated with A. lappa to a value close to the normal .The phytoprotective effect of Arctium lappa can be attributed to its free radical-scavenging activity and antioxidant effect, thus removing the injurious effects of toxic BPA and anise oil and induce hepatocyte regeneration (20).

\section{Protein profile:}

In the present study, the mixture of bisphenol A and anise oil caused toxicity and inflammation of liver, which induced significant decrease in protein profile. The decreased protein levels could be related to damage of cells caused by BPA. The decrease in protein content under stress induced by BPA may be attributed to BPAinduced oxidative stress in mitochondria and microsomes of cells. This can lead to various diseases, including cancer, infertility and neurodegenerative diseases ${ }^{(\mathbf{2 1})}$.

Most of serum proteins are synthesized in the liver. The liver is the main site of the conjugation and detoxification of drugs and other foreign substances. The hypoproteinemia observed in the present results revealed the hepatotoxic nature of BPA in liver cells. The synthesis of albumin is depressed in a variety of diseases particularly those of the liver. The plasma of patients with liver disease often shows a decrease in the ratio of albumin to globulins $(\mathrm{A} / \mathrm{G}$ ratio) ${ }^{(22)}$.

Albumin and most of globulins are released by the hepatocytes into the circulation ${ }^{(23)}$. But administration of the ethanolic extracts in phytoestrogens showed negative effects on male albino rats. It caused decrease in protein as a result of water depletion due to decreased intake and excessive loss, increased protein catabolism and increased protein excretion in urine. One of the gradients of anise, d-limonene is a naturally cyclic terpene and a major component of several plant essential oils. It causes decrease in protein as a result of increased excretion in urine. Meanwhile, treating with A. lappa, recorded an improvement in protein profile to the normal level. The hepatoprotective effect of A. lappa might be attributed to its antioxidant effect and free radical scavenging activity due to its high levels of flavonoids and polyphenolics. Also, these results may be related to the presence of mucilage ${ }^{(24)}$.

\section{Lipid profile:}

Results of the present study revealed a disturbance in lipid profile as reflected by the significant increase of all the parameters of lipid profile, except HDL-C level which showed a significant decrease in mixture-treated group when compared to control. BPA also found to stimulate lipid accumulation and up-regulate genes involved in lipid metabolism in adipocytes ${ }^{(25)}$. BPA can induce estrogenic activity in treated groups, where estrogens have a significant effect on serum cholesterol. The effect on cholesterol is probably due to an action of the hormone on the lipoproteins 
associated with cholesterol in the circulation, so altering the level of serum cholesterol (26). Mechanistically, anise or environmental BPA is a well-known endocrine-disrupting chemicals that bind to estrogen receptors (ER alpha and ER beta) and results in competition with estrogen and disruption of the lipid profile. BPA induces oxidative stress by ROS production that are known to alter lipid profile activity. Meanwhile, treating with A. lappa, improved lipid profile as compared to the mixture-treated animals. This effect might be related, in part, to its anti-oxidative activity, which decreases the oxidative stress on the hepatocytes, or to other unknown protective mechanism, such as the deflection in the fat accumulation, serum insulin and glucose or insulin resistance ${ }^{(27)}$. Cholesterol-diminishing activity of A. lappa is mainly in consequence of the reduction of its absorption in the intestinal tract via lowering pancreatic lipase and elevating lipoprotein lipase activity ${ }^{(28)}$. The results indicate that A. lappa could modulate blood lipid abnormalities.

\section{Kidney function:}

The results of this study demonstrated that rats of mixture groups showed significant increase the level of urea and creatinine. Korkmaz et al. ${ }^{(29)}$ reported that bisphenol-A (BPA), nonylphenol (NP), and octylphenol (OP) induced oxidative stress on the kidney tissue of male rats and that an antioxidant can prevent any possible oxidative stress. Vries $\boldsymbol{e t}$ al. ${ }^{(30)}$ recorded a reduced rate of renal clearance of 1-naphthol-beta -D glucuronide in BPA glucuronide, which was also excreted into the urine through the kidney. Estrogens appear to have an opposite effect on rats in administration of large amounts of estrogen where it reduces kidney weight and may produce cyst like degenerative changes in the juxtamedullary layer of the cortex (31). Prolonged administration of estrogen to rats induces an insignificant increase in the weight of the kidney and gives rise to "estrogen-dependent" renal tumors ${ }^{(32)}$.

The administration of the ethanolic extracts of plants to male albino rats showed some negative effects such as glomerular extrusion and glomerular collapse with resultant increased urinary space, dilated tubules, vacuolations in some epithelial lining of most of the tubules in the medulla and inflammatory cellular infiltration at some peritubular regions. In addition, oral administration of d-limonene increases the chance of hyperplasia and adenocarcinoma in rat kidney. D-limonene is recognized as an experimental carcinogen because it causes nephropathy and kidney tumors in male rats, that results from binding to $\mathrm{a}_{2} \mathrm{u}$-globulin in the kidney. Meanwhile, treating with A. lappa, recorded an improvement in kidney function to the normal level .The results indicate that A. lappa seed extract prevented oxidative damage and exerted antioxidant activity by scavenging existing ROS. In addition, treatment with A. lappa showed improvement in levels of serum urea, which could be due to decreased metabolic disturbances ${ }^{(33)}$.

\section{Hormones:}

In the present study, the mixture of bisphenol $\mathrm{A}$ and anise oil showed a significant increase in FSH and prolactin hormone levels of the rats. BPA caused hyperprolactinemia, which was progressively increased with time of the experiment that reached 30 days. Similar data were obtained by Rosmary et al. ${ }^{(34)}$ who stated that BPA has estrogen-like effect mimicked estradiol in inducing hyperprolactinemia in an estrogensensitive rat. The mechanism may indicate that BPA-induced hyperprolactinemia might be due to altering of estrogen receptors and/or estrogenresponsive genes that affect the lactotrophs in rats. Also, Helal et al. ${ }^{(35)}$ showed that the blood serum hormone levels of parental female rats were altered by BPA exposure. In the present study, it was found that BPA induced a significant elevation in FSH with concomitant reduction in LH levels with the two dose levels used. Differences in the response of FSH and LH to BPA could be due to differential sensitivity of the systems regulating FSH and $\mathrm{LH}$ secretion to BPA at the level of the pituitary or the hypothalamus. However, BPA could have hypothalamic actions and can alter levels of progesterone receptor expression within the medio-basal hypothalamus. This induces changes in neural systems that could impact upon gonadotrophin secretion.

The present data revealed that serum testosterone level recorded a significant decrease after treatment with BPA. BPA has adverse effects on testicular function by decreasing pituitary LH secretion and reducing Leydig cells steroidogenesis. There is also evidence that BPA interferes with LH receptor-legend binding. While anise oil indicated that these herbs may have gonadotropin-like action, which produces Leydig cell hypertrophy and hyperplasia and increased steroidogenic capacity. Exposure of the adult male rats to phytoestrogen diet disrupts spermatogenesis and increases germ cell apoptosis. Phytoestrogen is an estrogenic agent, directly or indirectly interferes with the physiological effect of estrogens and interfere with the function of male reproductive system. The main constituent of the anise oil anethole, has been considered as the active estrogenic agent. Anise oil also contains safrole, which lowers the level of androgen and leads to hormonal disturbance and 
decreases sperm count. Furthermore, it has been suggested that estrogen exposure interferes with the androgen receptor pathway and affect the late steps spermatogenesis. According to the traditional thinking, drinking anise by boys may be harmful to their reproductive system. Rats treated with anise oil had several histopathological changes, including in the Sertoli and Leydig cells. The destructive effect of anise oil may be related to its safrole content ${ }^{\left({ }^{(36}\right)}$. Ibrahim ${ }^{(37)}$ reported that some safrole (and other naturally occurring alkenylbenzenes) can undergo metabolic activation by sequential 1-hydroxylation and sulfation, resulting in reactive intermediates capable of forming DNA adducts and finally genotoxicity. A high phytoestrogen diet in male rats can also block spermatogenesis, induce germ cell apoptosis, and decrease the expression of ER $\alpha$ and AR in the cauda epididymis as well as increase lipoperoxidation in epididymal sperms. These effects are possibly mediated by disruption of the steroid regulation of the epididymis, resulting in decreased quality of sperm, and thereby reducing fecundity. Meanwhile, treating with A. lappa, recorded an improvement in the sexual hormones to the normal level. Treatment with A. lappa implicated many components of plant extracts as possible bioactive agents responsible for increasing endogenous testosterone levels and enhancing male sexual behavior. These include steroids and steroidal saponins, which may act as intermediaries in the steroidal pathway of androgen production.

Saponins may bind to hormone receptors, resulting in conformational changes that can enhance the physiological functions of the hormone, or can bind to enzymes involved in the synthesis of such hormones. Thus, enhancing their production ${ }^{(38)}$. In addition, flavonoids have been implicated in altering androgen levels and may also be responsible for enhancing male sexual behavior by enhancing testosterone synthesis or by preventing its metabolic degradation. This study indicated that Arctium lappa L. root contains sterols, flavonoids, phenols, saponins, lignans (such as arctiin), alkaloids, sugars (polysaccharides), vitamins, tannin, minerals, lactone, polyacetylenes and amino acids. The improvements in sexual function demonstrated in the current study might be due to the presence of such compounds in Arctium lappa L. root extracts (39).

\section{CONCLUSION}

It could be concluded that phytoestrogen and xenoestrogen have undesirable effects and it's recommended to minimize the utilization of these compound to protect people from its hazardous effects.

\section{REFERENCES}

1. Shore LS, Gurevitz M, Shemesh M (1993): Estorgen as an environmental pollutant. Bulletin of Environmental Contamination and Toxicology, 51: 361-6.

2. Desbrow C, Routledge EJ, Brighty GC (1998): Identification of estrogenic chemicals in STW effluent chemical fraction and in vitro biological screening. Sci Technol., 11: 1549-58.

3. Melzer D, Harries L, Cipelli R et al. (2011): Bisphenol A exposure is associated with in vivo estrogenic gene expression in adults. Environ. Health Perspect., 119: 1788-1793.

4. Richter CA, Birnabaum LS, Farabollini F et al. (2007): In vivo effect of bisphenol-A in laboratory rodent studies. Repord Toxicol., 24: 199-224.

5. Thomas S, Baynes K (1878): Editor-in-chief, William Robertson Smith. Anise", Encyclopædia Britannica, 9th ed., Vol. II, New York, Charles Scribner's Sons, Pp: 5758.

6. Sagdic O, Ozcan M (2003): Antibacterial activity of Turkish Spice hydrosols. Food Control, 14: 141-143.

7. Seleem T (2008): Rabbit productivity and reproductivity as affected by fenugreek in diets. The $1 \mathrm{st}$ Egyptian Conference on Rabbits Sciences, Pp: 142-153.

8. Ishikawa T, Fujimatu E, Kitajima J (2002): WaterSoluble Constituents of Anise: New Glucosides of Anethole Glycol and Its Related Compounds. Chemical \& Pharmaceutical Bulletin, 50(11): 1460-1466.

9. Rodrigues VM, Rosa MO, Meireles MA (2003): Supercritical extraction of essential oil from aniseed (Pimpinella anisum L.) using CO2: solubility, kinetics and composition data. J Agric Food Chem., 51 (6): 1518-1523.

10. Kemper KJ (2010): Burdock (Arctium lappa) The Longwood Herbal Task Force. http://www.mcp.edu/herbal/default.htm

11. Lewis WH (1977): Medical Botany Plants Affecting Man's Health New York: Wiley; https://www.amazon.com/Medical-Botany-AffectingWiley-Interscience-Publication/dp/0471861340.

12. Zhu Z, Yan J, Jiang $W$ et al. (2013): Arctigenin effectively ameliorates memory impairment in Alzheimer's disease model mice targeting both $\beta$ amyloid production and clearance. J Neurosci., 33: 13138-13149.

13. Friedwald's WT, Levy RI, Fredrickson DS et al. (1999): Estimation of the concentration of low-density lipoprotein cholesterol in plasma, without use of the preparative ultracentrifuge. Clin Chem., 18: 499-502.

14. Norbert WT (1995): Clinical guide to laboratory tested. $3^{\text {rd }}$ ed. Saunders W.B., Company, Philadelphia. https://onlinelibrary.wiley.com/doi/abs/10.1111/j.1537 -2995.1995.tb03571.x

15. Çabuk M, Alçiçek A, Bozkurt M et al. (2003): Antimicrobial properties of the essential oils isolated from aromatic plants and using possibility as alternative feed additives II. https://scholar.google.com > citations > user $=$ pGL8sjUAAAAJ

16. Jaeg JP, Perdu E, Dolol DL et al. (2004): Characterization of new Bisphenol-A metabolites 
produced by CDI mice liver microsome and 59 fractions. https://www.ncbi.nlm.nih.gov > pubmed

17. Inoue H, Yokota H, Taniyama H et al. (1999): 1Naphthol B-D-glucuronide formed interaluminally in rat small intestine mucosa and absorbed into the colon. Life Sci., 65: 1579-1588.

18. Abouseif HS (2016): Physiological change due to hepatotoxicity and the protective role of some medicinal plants. Beni-Suef Univ J Basic Apple Sci., 5: 134-146.

19. Lei JC, Yu JQ, Yin Y et al. (2012): Alantolactone induces activation of apoptosis in human hepatoma cells. Food Chem Toxicol., 50: 3313-3319.

20. Lin CC, Lin JM, Yang JJ (1996): Anti-inflammatory and radical scavenge effects of Arctium lappa. The American Journal of Chinese Medicine, 24: 127-137.

21. Mourad IM, Khadrawy YA (2012): The sensetivityof liver, kidney and testis of rats to oxidative stress induced by different doses of Bisphenol A. Intern J Life Sci Pharma Col Rev., 2: 19-28.

22. Robert K, Daryl KG, Peter A et al. (2000): Hormones of the Gonads. Harper Biochemistry, $25^{\text {th }}$ edition. Appleton and Lange Publishers, USA, Pp: 112-128.

23. Bo Lü and Ping $Z$ (2010): The effects of bisphenol $A$ on sex hormone levels of F0 female rats and F1 male rats during weaning period. Toxicological and Environmental Chemistry, 92: 1729-1733.

24. Chan YS, Cheng LN, Wu JH et al. (2010): A review of the pharmacological effects of Arctium lappa (burdock). Inflammopharmacol, doi: 10.1007/s 10787010-0062- 4

25. Ganong WF (2015): Review of Medical Physiology, $24^{\text {th }}$ edition, San Francisco- California. Appleton and Hange, Norwalk C T, Pp: 459-490.

26. Paul K, Annmargret OL, Christer W et al. (1999): Dissociation of athrogenesis from aortic accumulation of lipid pero-oxides in watanabe heritable hyperlipidemic rabbits. J Clin Invest., 104 (2): 213-220.

27. El-Newary SA, Sulieman AM, El-Attar SR et al. (2016). Hypolipidemic and antioxidant activity of the aqueous extract from the uneaten pulp of the fruit from Cordia dichotoma. J Nat Med., 70: 539-553.

28. Ahangarpour A, Ali-Akbari FR, Mohaghegh SM et al. (2016): Effects of Arctium lappa aqueous extract on lipid profile and hepatic enzyme levels of sucroseinduced metabolic syndrome in female rats. Braz J Pharm Sci., 52: 425-431.
29. Korkmaz A, Aydoğan M, Kolankaya D et al. (2011): Vitamin C coadministration augments bisphenol A, nonylphenol, and octylphenol induced oxidative damage on kidney of rats. Environmental Toxicology, 26 (4): 325-337.

30. Vries MH, Redegeld FA, Koster A S et al. (1989): Hepatic, intestinal and renal transport of1-naphthol-BD-glucuronide in utant rats with hereditary-conjugated hyperbillirubinemia. Naunyn-schmiedebergs Arch Pharmacol., 340: 588-59.

31. King RJB, Mainwaring WIP (1974): Kidney in Steroid-Cell Interactions. Baltimore, University Park Press, Pp: 247.

32. Li JJ, Kiricman H, Hunter RL (1996): Sex difference and gonadal hormone influence on Syrian hamster kidney esterase isozymes. J Histochem Cytochem., 17: 386-393.

33. Bakr ESH, EISawy NA (2014): Therapeutic role of aqueous extract of milk thistle (Silybum adans L.) and Burdock (Arctium lappa) in rats. VRI Bio Med Chem., 2: 20-28.

34. Rosmary S, Brown NG, Allen DL et al. (1997): The environmental estrogen Bisphenol-A stimulates prolactin release in vivo and in vitro. Endocrinology, 138: 1780-1786.

35. Helal EG, Badawi MM, Soliman GM et al. (2013): Physiological and Histopathological studies on Bisphenol-A compound as xenoestrogen in male albino rats. The Egyptian Journal of Hospital Medicine, 50: $127-136$.

36. Jeurissen SM (2007): Bioactivation and genotoxicity of the herbal constituents' safrole, estragole and methyleugenol. 1st ed., Wageningen University, Wageningen, the Netherlands, Pp: 166-70.

37. Ibrahim AAE (2008): Correlation between fennel -oranise- oil administration and damage to the testis of adult rats. Egyptian Journal of Biology, 10: 62-7.

38. Gauthaman K, Adaikan PG (2008): The hormonal effects of Tribulus terrestris andits role in the management of male erectile dysfunction-an evaluation using primates, rabbit and rat. Phytomedicine, 15: 4454.

39. Ratnasooriya WD, Fernando TS (2008): Effect of black tea brew of Camelliasinensis on sexual competence of male rats. J Ethnopharmacol., 118: 373 377. 